\title{
Current Opinion on the use of Direct Oral Anticoagulants for the Prophylaxis of Venous Thromboembolism among Medical Inpatients
}

\author{
Jane J Lee' \\ Sahar Memar Montazerin ${ }^{2}$ \\ Fahimehalsadat Shojaei ${ }^{2}$ \\ Gerald Chi iD ${ }^{2}$ \\ 'Baim Institute for Clinical Research, \\ Boston, MA, USA; ${ }^{2}$ Division of \\ Cardiovascular Medicine, Beth Israel \\ Deaconess Medical Center, Harvard \\ Medical School, Boston, MA, USA
}

Correspondence: Gerald Chi Division of Cardiovascular Medicine, Department of Medicine, Beth Israel Deaconess Medical Center, Harvard Medical School, 930 Commonwealth Avenue \#3, Boston, MA, 02215, USA Tel + $1617975-9952$

Fax $+1617975-9955$

Email geraldcchi@gmail.com

\begin{abstract}
Venous thromboembolism (VTE) is a known cause of morbidity and mortality, especially among acutely ill medical patients. Although VTE prophylaxis is part of postdischarge clinical care in surgical patients, there is controversy regarding its use in acutely ill medical patients and the current guideline statements suggest against its routine use. Recent clinical trials (APEX, MAGELLAN and MARINER) compared the safety and efficacy of direct oral anticoagulants (including betrixaban and rivaroxaban) with the standard of the care, enoxaparin, to identify the risk-benefit tradeoff. In this review, we summarized the key findings from these trials and substudies and recent updates in society guidelines regarding VTE prevention. In addition, we discussed the potential barriers, cost-effectiveness, and COVID-19 with respect to the implementation of extended-duration or post-discharge usage of direct oral anticoagulants.
\end{abstract}

Keywords: thromboembolic events, betrixaban, rivaroxaban, enoxaparin, major bleeding, medically ill

\section{Introduction}

Venous thromboembolism (VTE) is one of the causes of morbidity and mortality among medically ill patients even after discharge. It has been shown that medically ill patients (defined as patients hospitalized due to an acute medical illness such as acute decompensated heart failure, acute respiratory failure, acute infection, acute rheumatic disorder, or acute ischemic stroke) represent a population with heterogeneous predisposition to VTE. ${ }^{1}$ Recent studies have shown that approximately $75 \%$ of the VTE events occurred after index hospitalization and particularly with a median time-to-event of 20 days. $^{2}$ Treatment with thromboprophylaxis agents beyond the hospitalization period has been associated with a significant reduction in VTE event rates among high-risk surgical patients. However, whether this strategy can be used among medically ill individuals remains unclear.

To address this question, several recent clinical trials investigated the safety, efficacy, and optimal duration of thromboprophylaxis, as well as optimal agent to be used in this subset of patients. A summary of these trials is outlined in Table 1.

Multicenter, rAndomized, parallel Group Efficacy and safety study for the prevention of venous thromboembolism in hospitalized medically iLL patients comparing rivaroxabAN with enoxaparin (MAGELLAN) trial investigated extended-duration rivaroxaban versus standard-duration enoxaparin in reducing 
Table I Summary of Study and Baseline Characteristics

\begin{tabular}{|c|c|c|c|c|c|}
\hline \multicolumn{6}{|l|}{ Study Design } \\
\hline Characteristic & \multicolumn{3}{|l|}{ APEX } & MAGELLAN & MARINER \\
\hline \multirow[t]{2}{*}{ Sample Size } & \multicolumn{3}{|c|}{7513} & \multirow[t]{2}{*}{8101} & \multirow[t]{2}{*}{12,024} \\
\hline & $\begin{array}{l}\text { Cohort } \\
\text { I } \\
(3870)\end{array}$ & $\begin{array}{l}\text { Cohort } \\
2 \\
(5735)\end{array}$ & $\begin{array}{l}\text { Cohort } \\
3 \\
(6286)\end{array}$ & & \\
\hline $\begin{array}{l}\text { Eligibility } \\
\text { Criteria }\end{array}$ & \multicolumn{3}{|c|}{$\begin{array}{l}\text { Aged } \geq 40 \text { years, hospitalized for } \\
\text { an acute medical illness (heart } \\
\text { failure, respiratory failure, } \\
\text { infectious disease, rheumatic } \\
\text { disease, or ischemic stroke), with } \\
\text { expected hospitalization } \geq 3 \text { days } \\
\text { and reduced mobility: } \\
\text { - Aged } 40-60 \text { with a previous } \\
\text { VTE or cancer and an additional } \\
\text { VTE risk factor } \\
\text { - Aged } 60-74 \text { with either } \\
\text { D-Dimer level } \geq 2 \times \text { ULN within } 4 \\
\text { days before randomization or at } \\
\text { least two additional VTE risk } \\
\text { factors } \\
\text { - Aged } \geq 75 \text { with or without } \\
\text { additional risk factors } \\
\text { VTE risk factors include: } \\
\text { - Previous VTE or superficial vein } \\
\text { thrombosis } \\
\text { - Body mass index } \geq 35 \mathrm{~kg} / \mathrm{m}^{2} \\
\text { - Chronic venous insufficiency } \\
\text { - Lower extremity paresis, } \\
\text { hemiparesis, or hemiparalysis } \\
\text { - Hormone therapy } \\
\text { - History of cancer excluding } \\
\text { non-melanoma skin carcinoma } \\
\text { - Chronic heart failure ( } \mathrm{NYHA} \mathrm{III/} \\
\text { IV) } \\
\text { - Chronic respiratory failure } \\
\text { - Active collagen vascular disease } \\
\text { associated with limited mobility } \\
\text { - Acute infectious disease } \\
\text { contributing to hospitalization } \\
\text { - Current use of erythropoiesis } \\
\text { stimulating agents } \\
\text { - Inherited or acquired } \\
\text { thrombophilia } \\
\text { (1) }\end{array}$} & $\begin{array}{l}\text { Aged } \geq 40 \text { years, hospitalized for an acute } \\
\text { medical illness (heart failure, active cancer, } \\
\text { respiratory failure, infectious disease, } \\
\text { rheumatic disease, or ischemic stroke), had } \\
\text { reduced mobility with at least one additional } \\
\text { risk factor for VTE (not required for those } \\
\text { with active cancer, acute ischemic stroke } \\
\text { with lower extremity paresis or paralysis, or } \\
\text { NYHA class III/IV heart failure): } \\
\text { - Severe varicosis } \\
\text { - Chronic venous insufficiency } \\
\text { - History of cancer } \\
\text { - History of DVT or PE } \\
\text { - History of NYHA class III/IV heart failure } \\
\text { - Inherited or acquired thrombophilia } \\
\text { - Recent major surgery or serious trauma } \\
\text { - Hormone replacement therapy } \\
\text { - Advanced age } \geq 75 \text { years } \\
\text { - Body mass index } \geq 35 \mathrm{~kg} / \mathrm{m}^{2} \\
\text { - Acute infectious disease contributing to } \\
\text { hospitalization }\end{array}$ & $\begin{array}{l}\text { Aged } \geq 40 \text { years, hospitalized for } 3-10 \text { days } \\
\text { with an acute medical illness (heart failure } \\
\text { with EF }<45 \% \text {, active cancer, respiratory } \\
\text { insufficiency or exacerbation of chronic } \\
\text { obstructive pulmonary disease, infectious } \\
\text { disease, rheumatic disease, or ischemic } \\
\text { stroke), received thromboprophylaxis with } \\
\text { low-molecular-weight heparin or } \\
\text { unfractionated heparin during the index } \\
\text { hospitalization, and had additional VTE risk } \\
\text { factors for venous thromboembolism as } \\
\text { indicated by a total modified IMPROVE risk } \\
\text { score of } \geq 4 \text { or a score of } 2 \text { or } 3 \text { plus } \\
\text { a plasma D-dimer level of }>2 \times \text { ULN }\end{array}$ \\
\hline $\begin{array}{l}\text { Treatment Arm } \\
\text { I }\end{array}$ & \multicolumn{3}{|c|}{$\begin{array}{l}\text { Oral betrixaban } 80 \mathrm{mg} \text { once } \\
\text { daily for } 35 \text { to } 42 \text { days }\end{array}$} & $\begin{array}{c}\text { Oral rivaroxaban } 10 \text { mg once daily for } 35 \pm 4 \\
\text { days }\end{array}$ & $\begin{array}{c}\text { Oral rivaroxaban } 10 \mathrm{mg} \text { once daily for } 45 \\
\text { days }\end{array}$ \\
\hline $\begin{array}{l}\text { Treatment Arm } \\
2\end{array}$ & \multicolumn{3}{|c|}{$\begin{array}{l}\text { Subcutaneous Enoxaparin } \\
40 \text { mg once daily for } 10 \pm 4 \\
\text { days }\end{array}$} & $\begin{array}{l}\text { Subcutaneous enoxaparin } 40 \mathrm{mg} \text { once daily } \\
\text { for } 10 \pm 4 \text { days }\end{array}$ & Placebo for 45 days at hospital discharge \\
\hline
\end{tabular}

Abbreviations: DVT, deep vein thrombosis; EF, ejection fraction; IMPROVE, International Medical Prevention Registry on Venous Thromboembolism; ISTH, International Society on Thrombosis and Haemostasis; NYHA, New York Heart Association; PE, pulmonary embolism; ULN, upper limit of normal; VTE, venous thromboembolism. 
VTE events performed among medically ill patients ${ }^{3}$ and found that the extended-duration rivaroxaban administration was non-inferior to the standard-duration of enoxaparin in preventing asymptomatic proximal or symptomatic VTE. However, it was also associated with a higher rate of clinically relevant bleeding complications. ${ }^{4}$ Later, the Acute Medically Ill Venous Thromboembolism Prevention with Extended Duration Betrixaban (APEX) and Medically Ill Patient Assessment of Rivaroxaban versus Placebo in Reducing PostDischarge Venous Thrombo-Embolism Risk (MARINER) trials evaluated the safety and efficacy of extendedduration betrixaban and post-discharge rivaroxaban among medically ill patients, respectively. ${ }^{5,6}$ Herein, we aimed to 1) summarize the efficacy and safety of extended-duration betrixaban among post-discharge medically ill patients from the APEX trial and its substudies; 2) compare betrixaban with the standard of care (enoxaparin) and rivaroxaban; and 3) summarize MAGELLAN and MARINER trials and their respective substudies.

\section{Betrixaban in APEX Trial Various Endpoints of APEX Trial APEX Study Design and Main Findings}

The APEX study was a randomized, double-blind clinical trial that compared the safety and efficacy of extendedduration betrixaban with a short course of enoxaparin (ie, standard of care) for the VTE prophylaxis among patients at high risk for post-hospital discharge VTE. A total of 7513 participants with known risk factors for postdischarge VTE were randomized in a 1:1 ratio to receive either enoxaparin (40 mg once daily) or placebo for $10 \pm 4$ days followed by placebo or betrixaban ( $80 \mathrm{mg}$ once daily) for 35 to 42 days. Briefly, the outcomes of interest were analyzed in three cohorts: Cohort 1 only included patients with an elevated D-dimer level; Cohort 2 was comprised of patients aged at least 75 years or with an elevated D-dimer level; and Cohort 3 included all the participants. Efficacy was defined as the occurrence of symptomatic deep-vein thrombosis (proximal or distal), non-fatal pulmonary embolism (PE), or VTE-related death. Safety endpoints were defined as the occurrence of major bleeding. ${ }^{5}$ The study reported no significant differences between extended-duration betrixaban and a standard regimen of enoxaparin in the VTE composite $(6.9 \%$ vs $8.5 \%$; relative risk $(\mathrm{RR})=0.81 ; 95 \%$ confidence interval $(\mathrm{CI})=0.65-1.00$; $\mathrm{P}=0.054)$ or major bleeding $(0.6 \%$ vs $0.7 \% ; \mathrm{RR}=0.88$;
95\% CI $=0.44-1.76 ; \mathrm{P}=0.72$ ) in Cohort 1 . Exploratory analyses provided evidence suggesting a benefit for betrixaban in the Cohort $2(5.6 \%$ vs $7.1 \%$; RR $=0.80$ [0.66-0.98]; $\mathrm{P}=0.03)$ and the overall population $(5.3 \%$ vs $7.0 \%$; $\mathrm{RR}=0.76 ; 95 \% \mathrm{CI}=0.63-0.92 ; \mathrm{P}=0.006$ ). No statistically significant differences were observed between the two treatment groups among all the participants in terms of major bleeding $(0.7 \% \quad$ vs $\quad 0.6 \% ; \quad \mathrm{RR}=1.19 ; \quad 95 \%$ $\mathrm{CI}=0.67-2.12 ; \mathrm{P}=0.55)$. Notably, more clinically relevant non-major bleeding occurred in the betrixaban group (3.2\% vs $1.7 \%$; $\mathrm{RR}=1.89=95 \% \mathrm{CI}=1.38-2.59 ; \mathrm{P}<0.001)$. Intracranial bleeding was reported to be lower among them. ${ }^{7}$

It is noteworthy that there were discrepancies in APEX primary results between contract research organization (CRO) and academic research organizations (ARO), in which ARO analysis showed significant VTE reduction in patients with elevated D-dimer level (6.9\% vs $8.5 \%$; $\mathrm{RR}=0.802 ; 95 \% \mathrm{CI}=0.644-0.998 ; \mathrm{P}=0.048)$. The authors suggested resolving the disagreements in interpreting and implementing the statistical analysis plan (SAP) by placing a clear communication process among members of the executive committee, ARO, CRO, and the Sponsors. This communication process may continue prior to database lock. Once all the disagreements were resolved and consent regarding consensus on all the discrepancies was signed by the executive committee, the data can be unblended. ${ }^{8}$ In another analysis of the APEX trial using the Fine and Gray method for competing risks of non-VTE -related death, betrixaban remained to be associated with a lower VTE risk compared with enoxaparin (subdistribution $\mathrm{HR}=0.65 ; 95 \% \mathrm{CI}=0.42-0.99 ; \mathrm{P}=0.046)$. The competing risks, events that compete with the outcome of interest and may alter or preclude the possibility of their occurrence, are particularly important to be considered in cardiovascular clinical trials that enroll patients with multiple comorbidities that may not reach the primary outcomes of the study due to death or other health-related issues. The results of this analysis reinforced the efficacy of betrixaban in VTE prophylaxis. ${ }^{9}$

\section{Irreversible Bleeding and Thrombotic Events}

Fatal or irreversible event is a composite of safety (fatal bleeding or intracranial hemorrhage) and efficacy (cardiovascular death, myocardial infarction [MI], PE, or ischemic stroke) outcomes with permanent tissue damage or clinical harm. This post-hoc analysis of the APEX trial compared the composite of fatal or irreversible efficacy 
and safety events in the two treatment arms of the trial. Among patients with an elevated D-dimer level (Cohort 1), fatal or irreversible events were reduced by betrixaban versus enoxaparin at 42 days $(3.54 \%$ vs $4.80 \%$; hazard ratio $[\mathrm{HR}]=0.73 ; \mathrm{P}=0.033$ ) and 77 days $(4.36 \%$ vs $6.27 \% ; \mathrm{HR}=0.70 ; \mathrm{P}=0.005)$. In all patients (Cohort 3), betrixaban reduced fatal or irreversible events at 42 days $(2.90 \%$ vs $4.08 \% ; \mathrm{HR}=0.71 ; \mathrm{P}=0.006)$ and 77 days $(3.64 \%$ vs $5.17 \% ; \mathrm{HR}=0.70 ; \mathrm{P}=0.002)$. Extendedduration betrixaban demonstrated approximately $30 \%$ reduction in fatal or irreversible ischemic or bleeding events compared with standard-duration enoxaparin. Based on the results of this substudy of the trial, one fatal or irreversible event may be prevented if 65 patients are treated with extended-duration betrixaban versus enoxaparin. $^{10}$

\section{Major Adverse Cardiovascular Events}

This post-hoc analyses of APEX trial compared the major adverse cardiovascular events (MACE) among participants of two treatment regimens. At 42 days, betrixaban reduced MACE (cardiovascular death, MI, or stroke) compared with enoxaparin $(2.4 \%$ vs $3.5 \% ; \quad H R=0.69 ; \quad 95 \%$ $\mathrm{CI}=0.52-0.90 ; \mathrm{P}=0.006$; absolute risk reduction [ARR] $=1.1 \%$; number needed to treat $[\mathrm{NNT}]=91$ ). At 77 days, the benefit in MACE reduction remained unchanged $(2.9 \%$ vs $\quad 4.3 \% ; \quad \mathrm{HR}=0.68 ; \quad 95 \% \quad \mathrm{CI}=0.53-0.87 ; \quad \mathrm{P}=0.002$; $\mathrm{ARR}=1.4 \% ; \mathrm{NNT}=72$ ). Of note, the risk of cardiovascular death was lower in betrixaban group at 42 days $(2.0 \%$ vs $2.7 \% ; \quad \mathrm{HR}=0.72 ; \quad 95 \% \quad \mathrm{CI}=0.53-0.98 ; \quad \mathrm{P}=0.034 ;$ $\mathrm{ARR}=0.7 \% ; \mathrm{NNT}=143)$ and 77 days $(2.4 \%$ vs $3.3 \%$; $\mathrm{HR}=0.75 ; \quad 95 \% \quad \mathrm{CI}=0.57-0.98 ; \quad \mathrm{P}=0.038 ; \quad \mathrm{ARR}=0.9 \%$; $\mathrm{NNT}=112){ }^{11}$

\section{Stroke}

The stroke substudy of the APEX trial compared the efficacy of extended-duration factor $\mathrm{X}$ inhibitor, betrixaban, with standard-duration enoxaparin in the prevention of stroke among acutely ill hospitalized patients retrospectively. The data indicated fewer all-cause strokes $(0.54 \%$ vs $0.97 \% ; \mathrm{RR}=0.56 ; 95 \% \mathrm{CI}=0.32-0.96 ; \mathrm{P}=0.032)$ and ischemic strokes $(0.48 \%$ vs $0.91 \% ; \quad \mathrm{RR}=0.53 ; 95 \%$ $\mathrm{CI}=0.30-0.94 ; \mathrm{P}=0.026$ ) among patients treated with betrixaban, as compared to enoxaparin through 77 days of follow-up. The short-term stroke risk was unexpectedly high among acutely ill hospitalized patients, and the study demonstrated the effect of betrixaban in stroke prevention. $^{12}$

\section{Rehospitalization}

Rehospitalization is a clinically relevant endpoint that accounts for the totality of efficacy of hospital-associated VTE prophylaxis, as hospital readmission poses a negative impact on patient outcome and economic burden. In this post-hoc analysis, the rate of rehospitalization was compared between the two treatment strategies among APEX trial patients. Betrixaban reduced the risk of VTE-related rehospitalization at 42 days $(0.25 \%$ vs $0.75 \%)$ and at 77 days $(0.45 \%$ vs $1.04 \%$; $\mathrm{HR}=0.44 ; 95 \% \quad \mathrm{CI}=0.25-0.80$; $\mathrm{P}=0.0055)$ in the overall population. Full-dose betrixaban also reduced rehospitalization at 42 days $(0.24 \%$ vs $0.93 \%)$ and at 77 days $(0.46 \%$ vs $1.25 \%$; HR $=0.37 ; 95 \%$ $\mathrm{CI}=0.20-0.70 ; \mathrm{P}=0.0015)$. This study provided evidence for the health economic implications of betrixaban. ${ }^{13}$

\section{D-Dimer and Thrombus Burden}

D-dimer is a laboratory indicator of thrombus burden that reflects clot formation and lysis. With the baseline D-dimer level and DVT thrombus burden (ie, the number of involved venous beds) evaluated by compression ultrasound, the substudies investigated the relationship between thrombus extension after deep vein thrombosis (DVT) establishment and baseline D-dimer level. The data of these substudies demonstrated that compared with enoxaparin, betrixaban not only reduced the DVT risk at 42 days ( $\mathrm{RR}=0.76$; 95\% CI: 0.61-0.94; $\mathrm{P}=0.013$ ) but also diminished DVT thrombus burden $(\mathrm{P}=0.012)$. Additionally, baseline elevated D-dimer was associated with a 2-fold increased risk of DVT $(\mathrm{P}<0.001)$, as well as a greater thrombus burden $(\mathrm{P}<0.0001) .{ }^{14}$ Previously, the MAGELLAN trial demonstrated that patients with D-dimer levels more than the twice upper limit of normal were at 3.5-fold increased risk of VTE than patients with D-dimer concentration equal or lower than this cuff-off value. ${ }^{15}$ These findings also help explain the legacy phenomenon of extended anticoagulation, where the anticoagulant effect of betrixaban has persisted one month after its discontinuation. Elevated baseline D-dimer was also associated with a greater thrombus burden. ${ }^{14}$ Consistent with this data, another APEX substudy showed that elevated baseline D-dimer level, either as a continuous or as a categorical variable, was associated with an increase in the rate of VTE-related events. For every $0.25 \mu \mathrm{g} / \mathrm{mL}$ increase in D-dimer concentration, there was a $2 \%$ increase in the RR of VTE in both the betrixaban $(\mathrm{P}<0.001)$ and enoxaparin $(\mathrm{P}<0.001)$ treatment arms. Among patients with positive D-dimer (2 upper limits of 
normal; corresponding to $1.00 \mu \mathrm{g} / \mathrm{mL})$, betrixaban was associated with a lower VTE at 42 days (5.4\% vs $7.6 \%$; $\mathrm{OR}=0.69 ; 95 \% \mathrm{CI}: 0.55-0.88 ; \mathrm{P}=0.003$ ) when compared with enoxaparin. However, betrixaban administration failed to affect the D-dimer value. ${ }^{16}$

\section{Symptomatic VTE}

Given the exclusion of $15 \%$ of participants from the initial analysis of APEX due to missing or uninterpretable data on compressible ultrasound (CUS), the substudy aimed to minimize the missing data by applying a modified analysis. The modified analysis included symptomatic events (symptomatic proximal or distal DVT, non-fatal PE, or VTE-related death). Betrixaban reduced symptomatic VTE at 42 days $(\mathrm{HR}=0.65 ; 95 \% \mathrm{CI}: 0.42-0.99 ; \mathrm{P}=0.044)$ and at 77 days $(\mathrm{HR}=0.55 ; 95 \% \mathrm{CI}: 0.37-0.83 ; \mathrm{P}=0.003)$. Non-fatal PE was also significantly reduced at 77 days $(\mathrm{HR}=0.45 ; 95 \% \mathrm{CI}=0.21-0.99 ; \mathrm{P}=0.041)$. In the "astreated" analysis, betrixaban use decrease VTE related mortality through day $77(0.34 \%$ vs $0.79 \%$; HR $=0.46$; 95\% CI $=0.22-0.96 ; \mathrm{P}=0.035 ; \mathrm{ARR}=0.45 \% ; \mathrm{NNT}=223$ ). In terms of safety endpoints, betrixaban administration was not associated with an increase in major bleeding events in either modified intention-to-treat or as-treated analysis. $^{17}$

\section{Bleeding}

Bleeding is a known complication of anticoagulant medications and its severity should be taken into account while selecting an anticoagulant agent for individuals. The objective of this post-hoc analysis was to compare the severity and impact of bleeding complications between the two treatment arms of the APEX trial. There were similar rates of major or clinically relevant non-major (CRNM) bleeding resulting in new or prolonged hospitalization (major: $44.0 \%$ vs $28.6 \%$; CRNM: $12.1 \%$ vs $21.1 \%)$ or study treatment interruption or cessation (major: $72.0 \%$ vs $71.4 \%$; CRNM: $71.3 \%$ vs $68.4 \%$ ) between treatment arms ( $\mathrm{P}=$ not significant). Although extended-duration betrixaban resulted in a 2-fold increase in CRNM bleeds compared with standard-duration enoxaparin, the clinical sequelae were comparable between the two treatment regimens. Betrixaban was associated with a higher rate of gastrointestinal bleeding versus enoxaparin that was associated with a higher rate of intracranial bleeding. Also, the bleeding complications of betrixaban were comparable to those that were previously reported with other factor Xa inhibitors. ${ }^{18}$

\section{Subgroups of Interest \\ Patients with Past Medical History of VTE}

Patients with a history of previous VTE are at high risk of recurrent VTE events. This post-hoc analysis evaluated the safety and efficacy of betrixaban over enoxaparin among medically ill patients with and without a prior history of VTE. About $8 \%$ of patients had a prior VTE, which was associated with a 4-fold increased risk of VTE (odds ratio $[\mathrm{OR}]=4.03 ; 95 \% \mathrm{CI}=3.06-5.30 ; \mathrm{P}<0.001)$. Among subjects with a prior VTE, betrixaban reduced VTE risk by approximately $40 \% \quad(10.4 \%$ vs $18.9 \% ; \mathrm{RR}=0.57 ; 95 \%$ $\mathrm{CI}=0.38-0.86 ; \mathrm{P}=0.006 ; \mathrm{NNT}=12$ ). Betrixaban administration also resulted in a significant reduction in asymptomatic DVT among subjects with a history of VTE compared to enoxaparin $(9.4 \%$ vs $16.2 \%$; $\mathrm{RR}=0.63 ; 95 \%$ $\mathrm{CI}=0.41-0.96 ; \mathrm{P}=0.030 ; \mathrm{ARR}=6.8 \% ; \mathrm{NNT}=15)$. No significant differences were found between treatment arms in terms of bleeding complications among patients with a prior history of VTE $(0.7 \%$ vs $1.4 \% ; \mathrm{P}=0.44)$ and without a history of VTE $(0.7 \%$ vs $0.5 \% ; \mathrm{P}=0.34)$. Betrixaban administration was associated with a larger ARR among patients with a previous history of VTE compared with patients with no previous history of VTE. ${ }^{19}$

\section{Patients with Renal Insufficiency or Receiving P-Glycoprotein Inhibitors}

This substudy of the APEX trial compared the safety and efficacy of two doses of betrixaban (80 $\mathrm{mg}$ and $40 \mathrm{mg}$ ) with the standard of care (ie, enoxaparin) among acutely ill patients. $^{20}$ The reduced dose of betrixaban was administered to patients with severe renal insufficiency and those receiving a concomitant strong P-glycoprotein inhibitor. Among participants of Cohort 1, full dose of betrixaban significantly reduced VTE compared with standard dose of enoxaparin $\quad(6.27 \% \quad$ vs $\quad 8.39 \% ; \quad R R=0.74 ; \quad 95 \%$ $\mathrm{CI}=0.58-0.96 ; \mathrm{P}=0.023)$, and similarly in the entire population $(4.87 \%$ vs $7.06 \% ; \mathrm{RR}=0.70 ; 95 \% \mathrm{CI}=0.56-0.87$, $\mathrm{P}=0.001)$. These findings suggested that the efficacy of betrixaban is mainly driven by a full-dose stratum. The dosage of $40 \mathrm{mg}$ daily may be over-adjusted and was not associated with safer outcomes compared to full dosage. ${ }^{20}$

\section{Patients Admitted to Intensive Care Unit (ICU)}

The clinical decision to administer the best possible option to critically ill patients is challenging given the higher risk of bleeding complications, as well as the necessity of VTE thromboprophylaxis. In this substudy, the investigators compared the safety and efficacy of 
extended-duration betrixaban by the reduced duration of enoxaparin among 703 critically ill patients. As compared to the patients treated with reduced-duration of enoxaparin, critically ill patients who received extendedduration of betrixaban were less likely to develop VTE ( $4.27 \%$ vs $7.95 \%$; $\mathrm{P}=0.042)$ and had similar major bleeding rates $(1.14 \%$ vs $3.13 \% ; \mathrm{P}=0.07)$. Both VTE $(3.32 \%$ vs $8.33 \% ; \mathrm{P}=0.013)$ and major bleeding $(0.00 \%$ vs $3.26 \%$; $\mathrm{P}=0.003$ ) were reduced in the full-dose stratum (ie, patients who had no severe renal insufficiency or P-glycoprotein inhibitor use). In this population, the benefit of prophylaxis with betrixaban was driven by preventing asymptomatic thrombosis and offset by an elevated risk of non-major bleeding. ${ }^{21}$

\section{Patients with Cancer}

Cancer is a known risk factor for VTE and medically ill patients with cancer are at increased risk of developing VTE. Yet, bleeding is also one of the possible complications that should be taken into account while initiating the thromboprophylaxis medication in this category of patients. The objective of this substudy of APEX was to compare the safety and efficacy of betrixaban versus enoxaparin among medically ill patients with a current diagnosis of cancer. Among patients with cancer $(13 \%$ of APEX participants), VTE (5.7\% vs 6.2\%; RR $=0.99 ; 95 \%$ $\mathrm{CI}=0.59-1.64 ; \mathrm{P}=0.95)$, major bleeding $(0.8 \%$ vs $0.0 \%$; $\mathrm{P}=0.13$ ), and CRNM ( $2.0 \%$ vs $2.0 \% ; \mathrm{P}=0.96$ ) were similar between treatment arms. Among patients without cancer, betrixaban was associated with a lower VTE (4.2\% vs $6.0 \% ; \mathrm{RR}=0.71 ; 95 \% \mathrm{CI}=0.57-0.88 ; \mathrm{P}=0.002$ ) but higher CRNM rate than enoxaparin. No significant interaction by cancer was noted for VTE $(\mathrm{P}=0.36)$ or major bleeding $(\mathrm{P}=0.07){ }^{22}$

\section{Elderly Patients}

This substudy of the trial assessed the superiority of betrixaban over enoxaparin among medically ill patients who were 80 years and older. Among patients $\geq 80$ years old (37\% of APEX participants), net clinical benefit (NCB; a composite of VTE or major bleeding) was similar between treatment arms $(7.0 \%$ vs $8.4 \%$; RR $=0.82 ; 95 \%$ $\mathrm{CI}=0.62-1.10$ ). Among patients $<80$ years old, NCB was lower in betrixaban than enoxaparin $(5.0 \%$ vs $6.7 \%$; $\mathrm{RR}=0.75 ; 95 \% \mathrm{CI}=0.58-0.96 ; \mathrm{P}=0.024)$. In the elderly, the event rate of NCB was greater, but the risk reduction by betrixaban did not reach significance. No significant interaction by age was observed $(\mathrm{P}=0.33){ }^{23}$

\section{Biomarkers and Risk of Stroke or VTE NT-proBNP and Stroke Risk}

$\mathrm{N}$-terminal fragment of B-type natriuretic peptide (NTproBNP) is a clinical biomarker that its elevation has been associated with coronary artery disease, atrial fibrillation, and congestive heart failure. In this APEX substudy, the clinical value of this biomarker in the prediction of incident stroke was assessed among the participants of the APEX trial. NT-proBNP ( $\geq 1975 \mathrm{ng} / \mathrm{L})$ was independently associated with an increased risk of stroke at 77 days $(\mathrm{HR}=3.64 ; 95 \% \mathrm{CI}=1.35-9.83 ; \mathrm{P}=0.011)$ after adjusting for thromboprophylaxis, CHA2DS2-VASc components, creatinine clearance $(\mathrm{CrCl})$, D-dimer, C-Reactive Protein, and other stroke risk factors. Although significant interaction was not observed, betrixaban administration reduced the stroke risk by an estimated $60 \%$ compared to enoxaparin among patients with NT-proBNP $\geq 1975 \mathrm{ng} / \mathrm{L}$ $(0.77 \%$ vs $1.94 \%$ at 77 days; number needed to treat $=86)$. This substudy concluded that elevated NT-proBNP may be considered as an enrichment strategy in future adaptive trials of stroke prevention. ${ }^{24}$

\section{Hemoglobin Concentration and VTE Risk}

Given the overlap of risk factors between VTE and anemia, this post-hoc analysis assessed whether the addition of hemoglobin measurement to the International Medical Prevention Registry on Venous Thromboembolism (IMPROVE) score would improve its predictive value for VTE. Anemia, defined as a hemoglobin concentration lower than $12.5 \mathrm{~g} / \mathrm{dl}$ in men and $11.0 \mathrm{~g} / \mathrm{dl}$ in women, at baseline was associated with a greater risk of symptomatic VTE ( $\mathrm{RR}=1.94 ; 95 \% \mathrm{CI}=1.27-2.98 ; \mathrm{P}=0.002)$, symptomatic DVT ( $\mathrm{RR}=2.29 ; 95 \% \mathrm{CI}=1.12-4.68 ; \mathrm{P}=0.019)$, and non-fatal $\mathrm{PE} \quad(\mathrm{RR}=2.63 ; 95 \% \mathrm{CI}=1.22-5.65 ; \mathrm{P}=0.010)$. Anemia remained associated with an increased likelihood of VTE even after adjusting for thromboprophylaxis, D-dimer, and other VTE risk factors $(\mathrm{OR}=1.71 ; 95 \%$ $\mathrm{CI}=1.09-2.69 ; \mathrm{P}=0.020$ ). The inclusion of low hemoglobin also improved risk discrimination and reclassification in the IMPROVE score. ${ }^{25}$

\section{Albumin Concentration and VTE Risk}

Hypoalbuminemia, a decreased serum concentration of albumin $(<35 \mathrm{~g} / \mathrm{L})$, has been associated with poor prognosis in hospitalized patients. Although the pathophysiology behind this interaction remains unclear, albumin reduction may be an indicator of inflammation in the body or underlying kidney or liver disease. This substudy 
of the trial compared the efficacy and safety of betrixaban with enoxaparin among patients in various categories of serum albumin level. Among patients with low albumin level $(<35 \mathrm{~g} / \mathrm{L})$, betrixaban administration nonsignificantly reduced the VTE related events $(7.79 \%$ vs $10.27 \%$; absolute risk difference $=-2.48 \%$; $95 \% \quad \mathrm{CI}=$ $-5.57 \%-0.61 \%$; $\mathrm{RR}=0.76 ; 95 \% \mathrm{CI}=0.54-1.07 ; \mathrm{P}=0.12)$. On contrary, among patients with normal serum albumin level ( $\geq 35 \mathrm{~g} / \mathrm{L})$, betrixaban reduced VTE related events compared to enoxaparin $(4.41 \%$ vs $6.39 \%$; absolute risk difference $=-1.98 \% ; 95 \% \mathrm{CI}=-3.23 \%-0.73 \%]$; $\mathrm{RR}=0.69$; $95 \% \mathrm{CI}=0.54-0.87 ; \mathrm{P}=0.002)$. The statistically insignificant effect of betrixaban among the low albumin group may be due to inadequate sample size and power and not due to lack of interaction between albumin and the treatment. In agreement with this, there was no significant association between albumin and thromboprophylaxis medication ( $\mathrm{P}$ for interaction=0.70). Among hospital inpatients anticoagulated with betrixaban or enoxaparin, there was a stepwise increase in VTE risk with low levels of albumin $(\mathrm{P}<0.0001)$. Low albumin $(<35 \mathrm{~g} / \mathrm{L})$ was associated with 2-fold greater odds for VTE compared with the top quartile $(\geq 42 \mathrm{~g} / \mathrm{L}) \quad(\mathrm{OR}=2.12 ; 95 \% \quad \mathrm{CI}=1.59-2.82$; adjusted $\mathrm{OR}=2.08 ; 95 \% \mathrm{CI}=1.49-2.91)$. The addition of albumin measurement improved the performance of the IMPROVE score. $^{26}$

\section{Rivaroxaban in MAGELLAN and MARINER Trials MAGELLAN Trial}

MAGELLAN trial, the comparative study of extendedduration of rivaroxaban versus standard-duration of enoxaparin in reducing the VTE events performed among 8101 medically ill patients, ${ }^{3}$ showed that the standard-duration of rivaroxaban administration was non-inferior to standardduration of enoxaparin in terms of VTE prevention. However, the extended-duration rivaroxaban use was superior to enoxaparin and was also associated with a higher rate of clinically relevant bleeding complications. ${ }^{4}$

\section{MAGELLAN Substudy in Heart Failure Patients}

A post-hoc analysis of the MAGELLAN trial assessing the relationship between heart failure severity and VTE incidence rate demonstrated a higher rate of thromboembolic events among patients with more severe heart failure. This analysis included 2593 patients from the MAGELLAN trial with New York Heart Association class III or IV heart failure. The efficacy and safety of each treatment arm were evaluated, as well as the association between the heart failure severity (using pro-BNP short- term risk predictor and D-dimer as a long-term risk predictor) and VTE incidence rate. The study found an increased rate of VTE events among heart failure patients with higher pro-BNP levels up to 10 days and those with a higher D-dimer level up to 35 days in the enoxaparin/placebo group but failed to find such association in those receiving extended-duration of rivaroxaban. The author explained that this may be due to the preventive impact of rivaroxaban on VTE events. This data was further supported by the lower serum level of D-dimer in the rivaroxaban treatment arm. Extended use of rivaroxaban was associated with an increase in clinically relevant bleeding events across all the heart failure quartiles; however, this association was not statistically significant. $^{27}$

\section{MAGELLAN Exclusionary Criteria and Improved Benefit-Risk Profile of Rivaroxaban}

Another substudy of the MAGELLAN trial investigated the safety and efficacy of rivaroxaban among a subpopulation of this trial and after excluding patients at higher risk of bleeding complications. According to this substudy, patients with active cancer, bronchiectasis/pulmonary cavitation, peptic ulcer, dual antiplatelet therapy at baseline, or bleeding within 3 months were at high risk of bleeding, and therefore, were excluded from the analysis. The study revealed the superiority of rivaroxaban over enoxaparin/placebo at day 35 in terms of safety and efficacy. $^{28}$

\section{MAGELLAN Substudy in Medically III Patients Due to Infections}

In another analysis of the MAGELLAN trial, the safety and efficacy of rivaroxaban were compared with enoxaparin in 3173 medically ill hospitalized patients due to acute infectious disease. The study provided evidence for the superiority of rivaroxaban over enoxaparin in terms of efficacy $(4.4 \%$ vs $6.6 \%$; $R=0.50,95 \% \mathrm{CI}=0.45-0.92)$. However, enoxaparin showed a more favorable profile in terms of safety. ${ }^{29}$

\section{MAGELLAN Substudy and Role of D-Dimer in VTE Prediction}

In this analysis of the MAGELLAN, trial patients were categorized into two groups based on their D-dimer level. The findings of the study revealed the high predictive value of D-dimer for VTE events and the superiority of rivaroxaban over placebo in patients with a higher baseline 
D-dimer level. In multivariate analysis, after adjustment for potential confounders, baseline high D-dimer value was associated with increased risk of VTE approximately to the same extent of known VTE risk factors, such as cancer and advanced age. The frequency of VTE-related events was 3.5-fold higher among patients with baseline D-dimer levels more than twice the normal range. ${ }^{15}$

\section{MARINER Trial}

The MARINER study, a randomized, double-blind, placebo-controlled trial, evaluated the safety and efficacy of rivaroxaban among post-discharge medically ill patients. This trial reported that a combination of modified IMPROVE score and D-dimer level was effective in identifying individuals at high risk of VTE development. Patients with modified IMPROVE score $>4$ or 2 , 3 plus a plasma D-dimer level more than the twice upper limit of the normal range were included in the study. A total of 12,024 patients were randomized in a ratio of $1: 1$ to receive either rivaroxaban $(10 \mathrm{mg}$ if $\mathrm{CrCl} \geq 50 \mathrm{~mL} / \mathrm{min}$ or $7.5 \mathrm{mg}$ if $30 \mathrm{~mL} / \mathrm{min} \leq \mathrm{CrCl}<$ $50 \mathrm{~mL} / \mathrm{min}$ ) or placebo daily for 45 days. The efficacy was defined as a combination of VTE (lower extremity deep-vein thrombosis and non-fatal PE) and VTErelated death. The safety outcome was major bleeding. ${ }^{6}$ The study demonstrated that rivaroxaban administration was not associated with a statistically significant reduction in VTE-related events, as compared to the placebo $(0.83 \%$ vs $1.10 \%$; $\mathrm{HR}=0.76$; 95\% $\mathrm{CI}=0.52-1.09 ; \mathrm{P}=0.14)$. However, it resulted in fewer symptomatic VTE than placebo $(0.18 \%$ vs $0.42 \% ; \mathrm{HR}=0.44 ; 95 \% \mathrm{CI}=0.22-0.89$ ). The primary safety outcome was also comparable to that of placebo $(0.28 \% \quad$ vs $\quad 0.15 \% ; \quad \mathrm{HR}=1.88 ; \quad 95 \% \quad \mathrm{CI}=0.84-4.23)$. Given that rivaroxaban administration was not associated with a significant reduction in VTE-related mortality, its extended use may not be clinical beneficial. ${ }^{30}$

\section{MARINER Substudy}

A substudy of MARINER, evaluating the efficacy of rivaroxaban, as a composite of symptomatic VTE, MI, non-hemorrhagic stroke, and cardiovascular death, revealed a $28 \%$ reduction in fatal and non-major thromboembolic events $(1.28 \%$ in rivaroxaban vs $1.77 \%$ in placebo; $\mathrm{HR}=0.72 ; 95 \% \quad \mathrm{CI}=0.52-1.00$; $\mathrm{P}=0.049$ ). This analysis also reported an equivalent increase in major bleeding in patients receiving rivaroxaban, as compared to those who received placebo
$(027 \%$ vs $0.18 \% ; \mathrm{HR}=1.44 ; 95 \% \mathrm{CI}=0.62$ to 3.37 ; $\mathrm{P}=0.398$ ). This study showed a $\mathrm{NCB}$ of $0.40 \%$ via using rivaroxaban $10 \mathrm{mg}$ daily post-discharge among acutely ill medical patients $(\mathrm{ARR}=0.49 \%$, absolute risk of bleeding $=0.09 \%){ }^{31}$

\section{VTE and Bleeding Prediction}

IMPROVE score is a valid risk assessment tool that identifies the hospitalized, medically ill patients at high risk for the development of VTE. In one of the substudies of the APEX trial, the investigator evaluated whether the addition of D-dimer value to the IMPROVE score improves its predictive value in the determination of the high-risk group. Shortly, the study assessed the relationship between elevated D-dimer and IMPROVE score with VTE-related events among 7441 APEX participants. The results of this substudy demonstrated that the D-dimer value was independently associated with symptomatic VTE at 77 days $(\mathrm{HR}=2.22 ; 95 \% \mathrm{CI}=1.38-5.38 ; \mathrm{P}=0.0010)$. The addition of D-dimer to the IMPROVE score (IMPROVEDD score) was found to have enhanced performance in discrimination and reclassification. Patients with IMPROVEDD score $\geq 2$ had a greater risk of symptomatic VTE than those with a score of $0-1 \quad(\mathrm{HR}=2.73 ; 95 \% \mathrm{CI}=1.52-4.90 ; \mathrm{P}=0.0007)$, supporting its usefulness in identifying high-risk patients. The weight for D-dimer in the IMPROVEDD score aligned with the enrollment criteria of the MARINER trial, in which patients with IMPROVE $\geq 4$ or $2-3$ plus positive D-dimer were enrolled.

Among the APEX trial and its substudies, as well as MARINER and MAGELLAN trials, there were subgroups of patients who were at high risk of VTE development but are not identified by the current risk assessment tools. It included patients with 1) high baseline plasma level of D-dimer, 2) prior history of VTE, 3) anemia and low albumin level at the time of hospitalization, 5) severe heart failure defined based on the level of baseline NTproBNP, and 6) patients with active cancer.

Besides predicting the occurrence of VTE, another critical consideration to initiate the extended-duration anticoagulant agent is a prediction of bleeding complications. Although the three aforementioned trials excluded patients at high risk of major bleeding, the introduction of an effective predictive tool may be more helpful in clinical practice. Based on the findings from the three aforementioned trial and their 
substudies, bleeding complications were more frequently observed among patients with active cancer, bronchiectasis/pulmonary cavitation, peptic ulcer, dual antiplatelet therapy at baseline, or bleeding within 3 months, and those with IMPROVE score 4 or higher.

Collectively, adding additional criteria to increase the sensitivity of the IMPROVE score and considering a joint VTE-bleeding risk assessment tool at the time of administering the anticoagulant agent may be helpful in targeting high-risk medically ill patients for extended-duration of VTE prophylaxis. In addition, given the limitation of traditional risk assessment tools and the outperformance of machine learning in VTE prediction compared to IMPROVE score in terms of discrimination (c-statistic $=0.69,0.68$, and 0.59) and calibration (HosmerLemeshow goodness-of-fit $\mathrm{P}=0.06,0.44$, and $<0.001){ }^{32}$ the use of machine learning models and the addition of baseline value of D-dimer, hemoglobin concentration, albumin, and creatinine were suggested for the risk prediction of VTE among this population. Furthermore, these VTE risk score predictive tools undergo impact analysis in large population studies to be validated externally.

\section{Guideline Statements Regarding VTE Prevention}

Currently, there is no united point of view regarding VTE risk assessment and VTE prophylaxis. VTE and bleeding risk evaluation prior to initiation of prophylaxis has been recommended by the American College of Physicians (ACP). ${ }^{33}$ The American College of Chest Physicians (ACCP) recommended against pharmacologic VTE prophylaxis in acutely ill medical patients who are at low risk of VTE or at high risk of bleeding complications. ${ }^{34}$ The American Society of Hematology (ASH) guideline released in 2018 suggests against administering direct oral anticoagulant agents (DOACs) in inpatient settings, as well as the extended use of overall anticoagulant agents among acutely ill medical patients. The guideline panelists argued that the DOACs resulted in a comparable reduction in VTE-related mortality compared with enoxaparin and unfractionated heparin but were associated with an increased risk of bleeding complications in the recent trials. $^{35}$ In line with this argument, pooled data from two meta-analyses have shown similar results. ${ }^{36,37}$ According to this data, for every 1000 acutely ill medical patients who receive extended-duration of thromboprophylaxis, 2.3 symptomatic DVT events, as well as 1.5 non-fatal PE events, would be prevented, but at the cost of adding four major bleeding events. ${ }^{37}$ The North American Thrombosis Forum (NATF) comprised of worldwide experts provided a consensus document on the appropriate use of oral anticoagulants in medically ill patients. Based on this consensus document: 1) VTE prophylaxis should be taken into account based on measuring the VTE risk per a validated risk assessment tool; 2) VTE risk to be discussed with patients and their families; 3) Extended VTE prophylaxis should be taken into account when the VTE risk remains high post discharge; 4) Extended VTE prophylaxis with an Food and Drug Administration (FDA)approved agent is recommended when the risk is high; 5) A "meds-to-beds" program approach that includes steps to increase patients' compliance and decrease financial barriers to be applied; 6) Patients receiving extended VTE prophylaxis followed by either physicians or pharmacists via using a structured management system. ${ }^{38}$

\section{Comparison of Betrixaban, Rivaroxaban, and Enoxaparin in Terms of Safety and Efficacy}

Figure 1 summarized the comparison between DOAC and enoxaparin with respect to symptomatic VTE, nonfatal PE, symptomatic DVT, VTE-related death, myocardial infarction, major bleeding, clinically relevant non-major bleeding, and non-hemorrhagic stroke based on the results from APEX, MARINER, and MAGELLAN trials. It is notable that patients who received DOAC had a numerically lower rate of symptomatic VTE, non-fatal PE, symptomatic DVT, VTErelated death, and non-hemorrhagic stroke, but a numerically higher rate of major bleeding and clinically relevant non-major bleeding. Meta-analysis and bivariate analysis have been performed to systematically collate the evidence and estimate the benefit and risk of DOAC versus enoxaparin. A systematic review and meta-analysis of previous trials with a total of 34,068 acutely ill patients confirmed the efficacy of anticoagulant agents administered beyond the hospitalization period for decreasing symptomatic DVT and non-fatal PE. However, there was a controversy regarding the safety of these agents among this population. Betrixaban was the only agent that was not associated with an increased risk of major bleeding and, therefore, would be a safer option. ${ }^{37}$ In line with this study, the APEX substudy compared the efficacy and safety of 

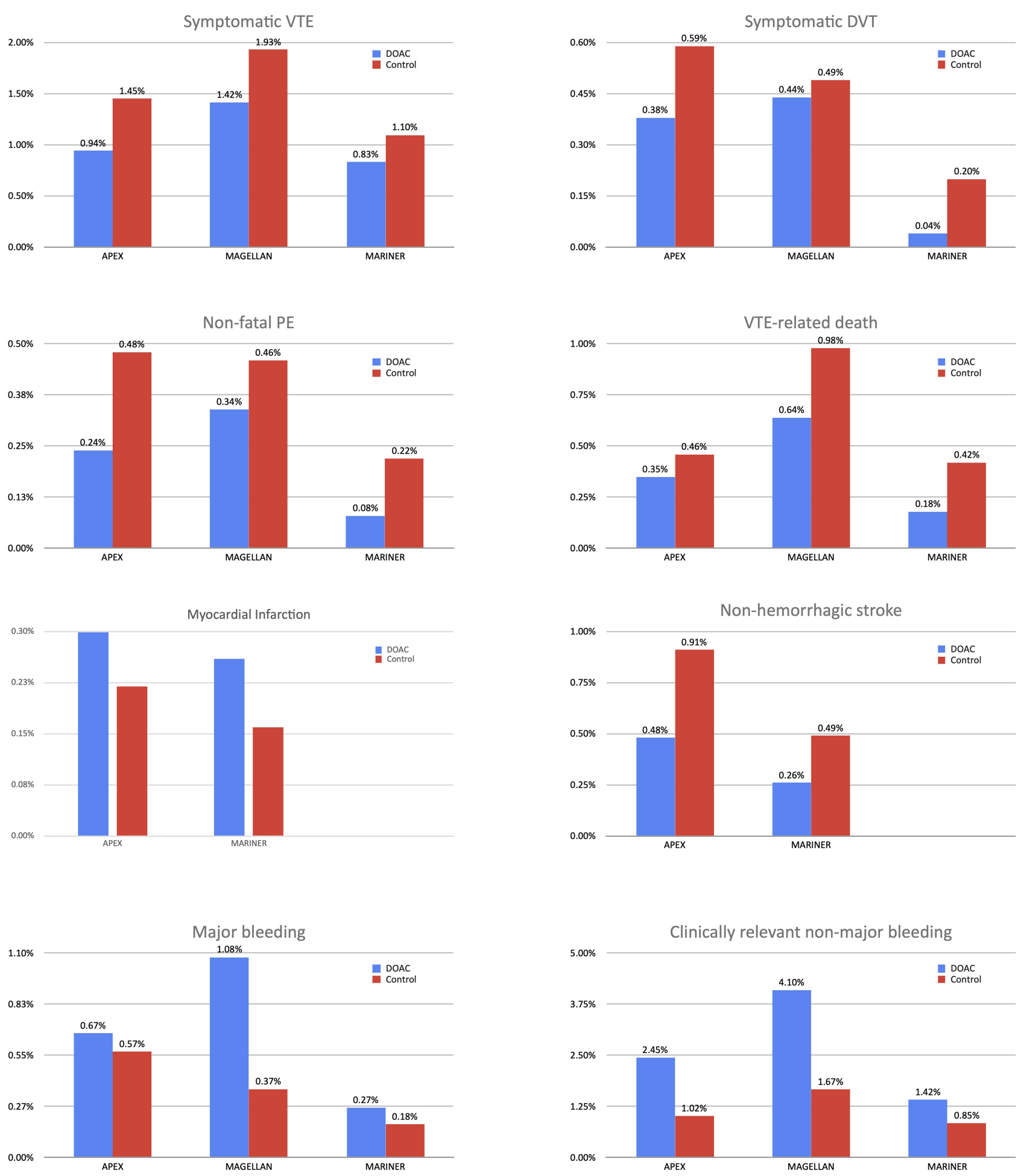

Figure I Comparison of incidence of VTE-related events between DOAC and control across different studies.

various anticoagulant regimens (extended-duration enoxaparin, apixaban, rivaroxaban, and betrixaban) via using bivariate analysis assuming nonlinear relationship between the efficacy and safety endpoints. The data supported the superiority of full-dose betrixaban over enoxaparin with respect to benefit-risk tradeoff. Other regimens (extended enoxaparin, apixaban, and rivaroxaban) did not show a favorable net benefit over shorter-duration enoxaparin. ${ }^{39}$ Betrixaban, a novel factor $\mathrm{Xa}$ inhibitor, achieved an $\mathrm{NCB}$ in 
reducing the VTE without increasing the major bleeding among the overall study population of the APEX trial. $^{7}$ This agent exerts its effect by preventing the conversion of prothrombin to thrombin. Also, betrixaban, as compared with other factor Xa inhibitors, such as rivaroxaban and apixaban, possess a better bioavailability profile and undergoes a minimal liver metabolism.

Table 2 compares the pharmacokinetics of betrixaban with rivaroxaban. Renal impairment is a known predisposing factor for both VTE and bleeding events. The risk of bleeding would be particularly higher if an unadjusted dose of the medication is used. Since the optimal dose of rivaroxaban and betrixaban in acutely ill medical patients with renal insufficiency is unknown in the MARINER trial, a substudy of MAGELLAN and the APEX evaluated an adjusted dose of these medications. These two trials reported similar results. The administration of rivaroxaban $7.5 \mathrm{mg}$ daily was associated with a higher rate of bleeding complications compared to the $10 \mathrm{mg}$ dose with no change in VTE prevention. The authors explained that the observed increase in bleeding complications was presumably due to similar rivaroxaban concentrations with both dosages. ${ }^{40}$ The reduced dose of betrixaban was associated with failure in VTE prevention, as well as an increase in major or CRNM events. ${ }^{20}$ Although the efficacy of extended-duration betrixaban was similar to extendedduration rivaroxaban in reducing the risk of VTE-related events, the safety profile of betrixaban in major bleeding events was favorable. Extended-duration rivaroxaban was associated with a higher risk of bleeding complications. MAGELLAN trial showed that an increase in central D-dimer concentration was associated with higher benefits from rivaroxaban over enoxaparin. Similar to betrixaban, rivaroxaban was associated with a significant reduction among patients with elevated D-dimer levels. ${ }^{16}$ Another meta-analysis, published after launching the MARINER trial, demonstrated that the VTE preventive effect of

Table 2 Pharmacokinetics of Betrixaban versus Other Anticoagulants

\begin{tabular}{|l|c|c|c|}
\hline \multicolumn{4}{|l|}{ Pharmacokinetics of Major Anticoagulants } \\
\hline Element & Betrixaban & Rivaroxaban & Enoxaparin \\
\hline Hepatic metabolism (\%) & $<1$ & 51 & 100 \\
\hline Renal excretion (\%) & 11 & 36 & 40 \\
\hline Half-life (h) & $19-27$ & $5-9$ & $4.5-12$ \\
\hline
\end{tabular}

these agents $(0.46$; number-needed-to-treat=218) was equivalent to their excess risk of bleeding ( $0.31 \%$; number-needed-to-harm=323), resulting in an estimated NCB of $15 \%$. This data provided evidence for the use of inhospital VTE prophylactic agents when the risk of symptomatic VTE outweigh the risk of bleeding complications. $^{36}$

The efficacy and safety of DOAC comparing to enoxaparin in specific subgroups have been studied in a previous meta-analysis and summarized in Figures 2 and $3 .^{41}$ With respect to efficacy, patients with D-dimer $>2 \times$ upper limit of normal (ULN) had a greater VTE reduction (risk difference $[\mathrm{RD}]=-2.39 \% \quad[-3.57 \%$ to $-1.21 \%])$ than those with $\leq 2 \times \quad \mathrm{ULN} \quad(\mathrm{RD}=-0.26 \%$ $[-1.08 \%$ to $0.56 \%])$. Similarly, patients aged $\geq 75$ years had a greater VTE reduction $(\mathrm{RD}=-2.29 \%[-3.49 \%$ to $-1.09 \%])$ than those aged $<75$ years $(\mathrm{RD}=-0.63 \%$ $[-1.70 \%$ to $0.44 \%])$. The efficacy of DOAC was homogeneous across the remaining subgroups such as sex, acute heart failure, acute respiratory failure, acute infectious disease, acute inflammatory/rheumatic disease, and acute ischemic stroke. With respect to safety, females had a higher rate of major bleeding when anticoagulated with betrixaban or rivaroxaban $(\mathrm{RD}=0.29 \%[0.05 \%$ to $0.52 \%])$, whereas the major bleeding risk was similar between betrixaban or rivaroxaban and enoxaparin among males $(\mathrm{RD}=-0.04 \% \quad[-0.29 \%$ to $0.21 \%])$. Among patients admitted with acute respiratory failure, the bleeding risk was similar between betrixaban or rivaroxaban and enoxaparin $(\mathrm{RD}=-0.18 \%[-0.56 \%$ to $0.20 \%])$. In contrast, betrixaban or rivaroxaban was associated with increased major bleeding among those without acute respiratory failure on hospitalization $(\mathrm{RD}=0.21 \%[0.02 \%$ to $0.40 \%]$ ). These patient subsets may be of interest when considering the benefit-harm profile of anticoagulation with DOAC.

\section{Cost-Effectiveness of Betrixaban}

The use of VTE is an economic burden worldwide; therefore, a strategy preventing its occurrence would benefit the health system and the economy. A study using real-world data (2014 National Inpatient Sample) with a total of $1,849,535$ acutely ill medical patients revealed that approximately $407,095(22.0 \%)$ of these patients were at high risk of VTE events. To identify these patients, the study used the modified IMPROVE VTE risk score, which defined the high-risk group as those with a score equal to or higher than four. These data suggested that a large population of acutely ill medical patients may benefit 

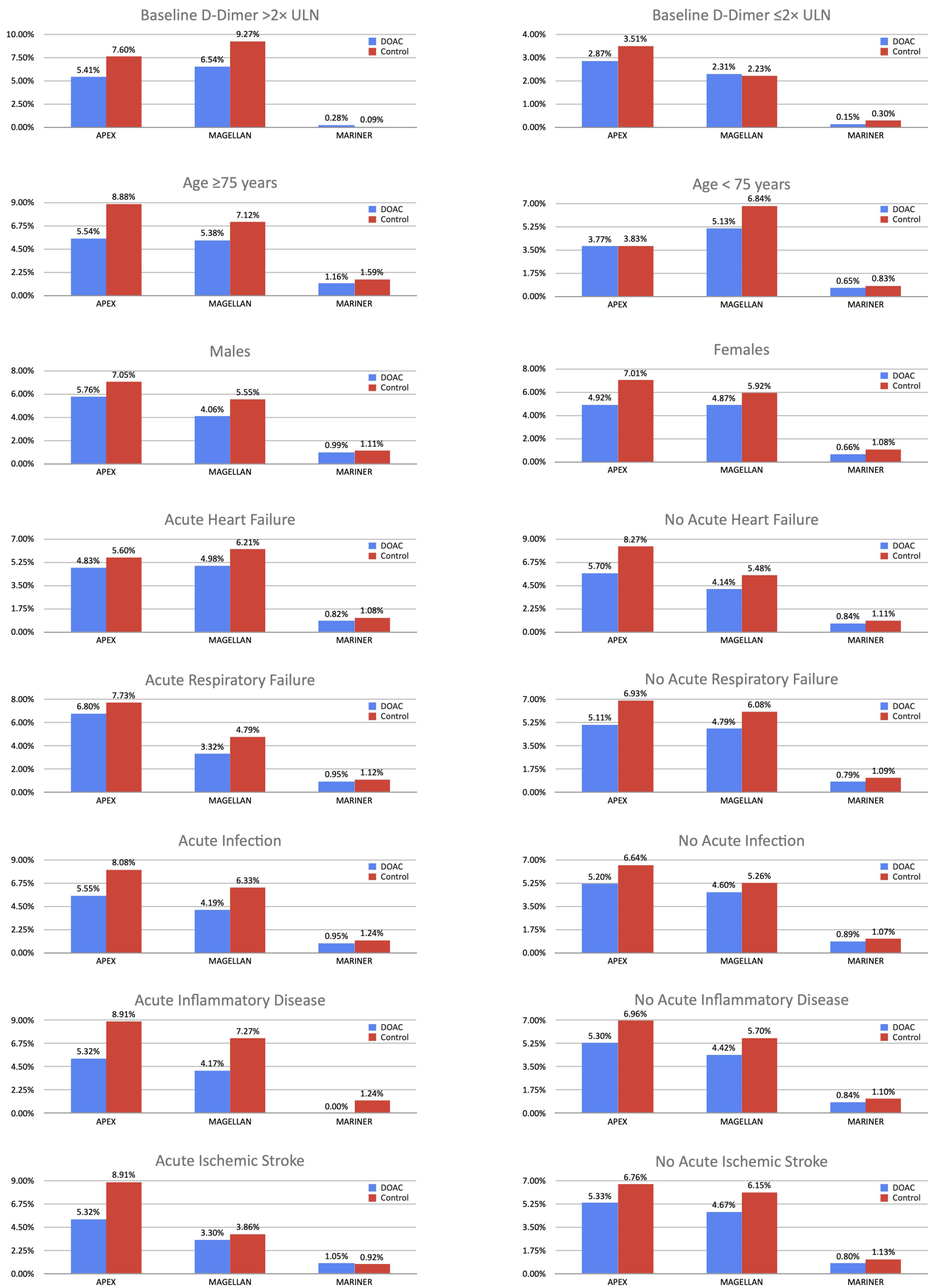

Figure 2 Subgroup analysis: Comparison of incidence of VTE between DOAC and control. 

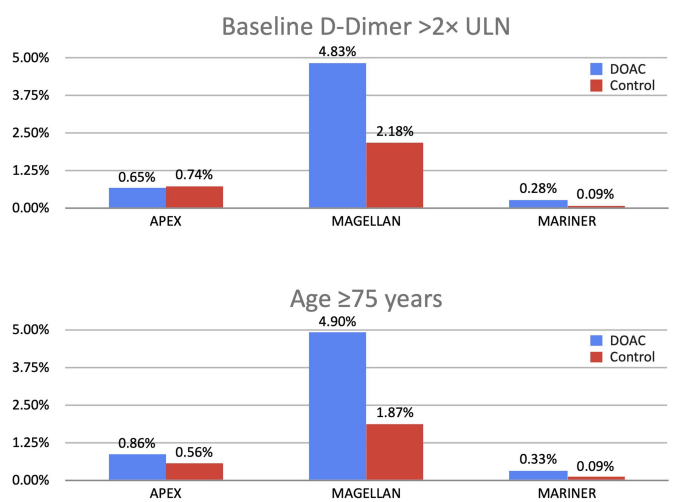

Males

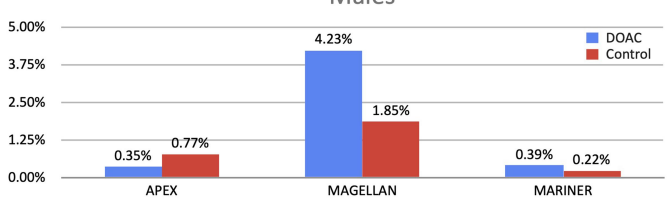

Acute Heart Failure

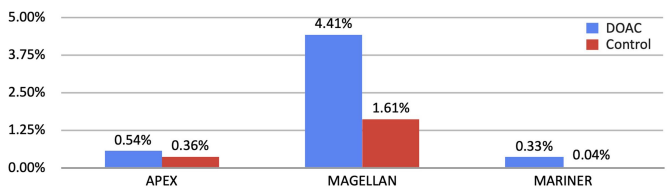

Acute Respiratory Failure

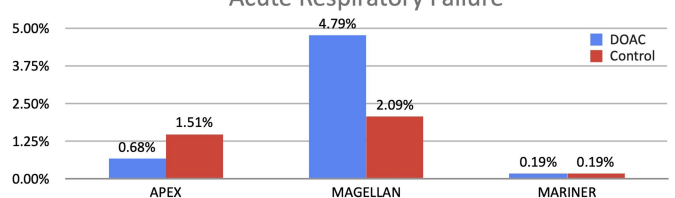

Acute Infection

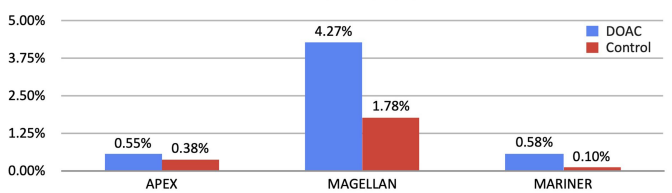

Acute Inflammatory Disease

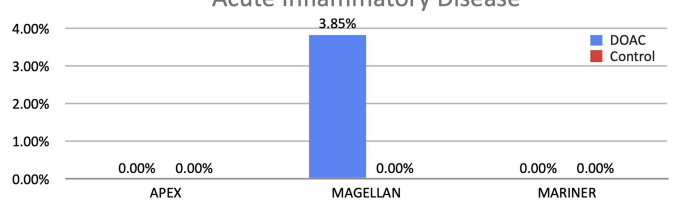

Acute Ischemic Stroke

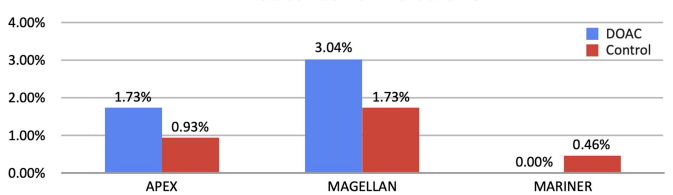

Baseline D-Dimer $\leq 2 \times$ ULN

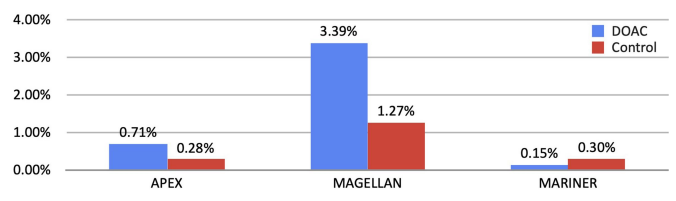

Age $<75$ years
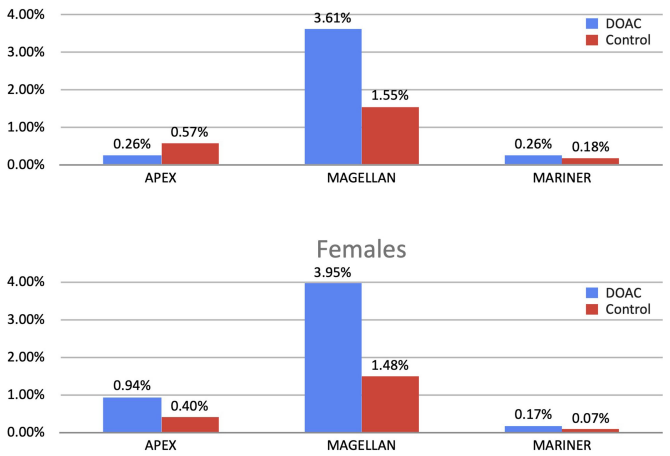

No Acute Heart Failure
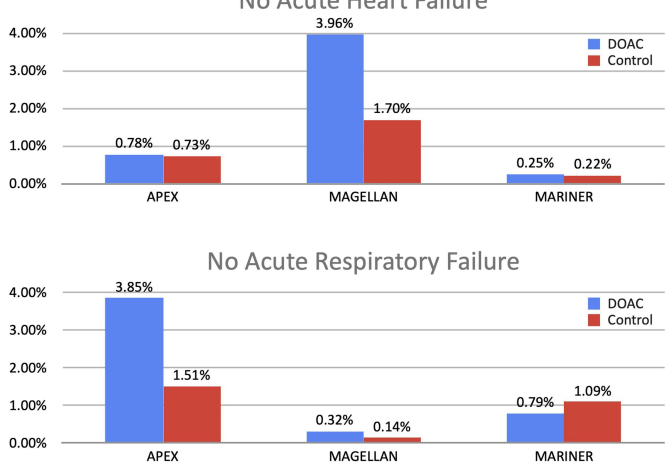

No Acute Infection

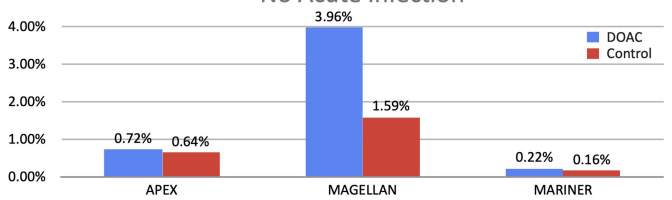

No Acute Inflammatory Disease

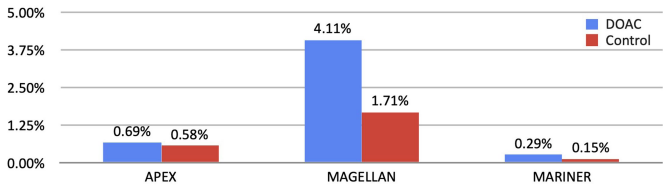

No Acute Ischemic Stroke

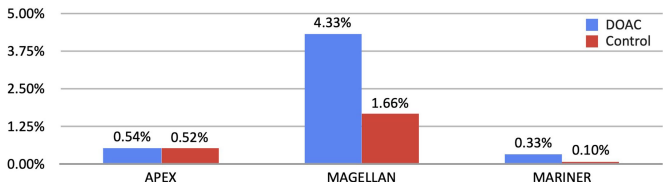

Figure 3 Subgroup analysis: Comparison of incidence of major bleeding between DOAC and control. 
from the extended-duration of thromboprophylaxis medications. ${ }^{42}$

A study estimating the cost-effectiveness of extendedduration of betrixaban for VTE prophylaxis among medically ill patients showed that it will save $£ 1.29$ million annually in Year 1 and $£ 23.00$ million in Year 5 to the United Kingdom health system. ${ }^{43}$ Another survey revealed that betrixaban is superior to enoxaparin in regards to costeffectiveness. As stated by the author, betrixaban administration was associated with saving 784 US dollars, as well as an increase of 0.017 in the quality-adjusted life year index per patient. ${ }^{44}$ Despite the favorable costeffectiveness, betrixaban has been discontinued and withdrawn from the market for independent business reasons from the manufacturer.

\section{Barriers Against the Post-Discharge VTE Prevention}

Although there is evidence suggesting the benefits of post-discharge anticoagulant therapies, there are obstacles in different levels of health system inhibiting physicians from implementing this strategy. First, the latest ASH guideline recommended against the use of extended-duration VTE prophylaxis due to bleeding complications and the low absolute reduction in VTE. Second, there is a lack of an appropriate risk assessment tool for predicting the VTE-bleeding risk of patients. Third, there is no system reassuring patient's adherence to the medication, and a lack of suitable educational system for patients and their families.

\section{COVID-I 9 VTE Prophylaxis}

\section{Post-Discharge}

Since early 2020, the COVID-19 pandemic has resulted in catastrophic morbidity and mortality. COVID-19related VTE events played a huge role in this morbidity. Studies have shown that patients infected with COVID-19 were at higher risk of developing thromboembolic events. The incidence was even higher among patients hospitalized in ICU. ${ }^{45-48}$ For example, a cohort study of 198 hospitalized patients with COVID-19 reported that the cumulative incidence of VTE at 7 days of admission was $16 \%$. Intriguingly, the incidence tended to increase over the course of hospitalization and was $42 \%$ at 21 days of admission. The cumulative incidence was even higher and reached $59 \%$ in COVID-19 patients hospitalized in ICU at 21 days of admission. ${ }^{45}$ The exact mechanisms of this hypercoagulability among patients with COVID-19 infection are still not completely understood. Since the thrombotic events occur despite the thromboprophylaxis treatment, ${ }^{49}$ it is hypothesized that a prophylactic dose of anticoagulation failed to maintain an appropriate anticoagulant environment among COVID-19 patients and, therefore, a higher dose or longer period of anticoagulation may be required. However, anticoagulation therapy should be use with caution as the ICU patients are generally more prone to experience complications, such as bleeding, in the case of unnecessary higher anticoagulation dose. Further research on the effect of administration of postdischarge anticoagulation therapy among patients with COVID-19 is needed to further understand the risk of anticoagulation therapy in this population. Table 3 describes the various society guideline recommendations for the management of COVID-19 coagulopathy post-discharge.

\section{Conclusion}

The data from National Inpatient Sample showed a high number of patients at risk of VTE complications. ${ }^{42}$ In addition, the increased risk of mortality was observed in one of the APEX substudies $(\mathrm{HR}=2.87 ; 95 \% \mathrm{CI}=1.48-5.57, \mathrm{P}=0.001)$ at 77 days among medically ill individuals who developed asymptomatic DVT. ${ }^{50}$ The independent clinical benefits of rivaroxaban and betrixaban in reducing the rate of rehospitalization and $\mathrm{MACE}^{51}$ facilitated the use of these medications for a period beyond the hospitalization period. Given the specific inclusion criteria of each trial and including acutely ill patients who were 40 years old or older with immobilization and other potential risk factors for VTE, the results of these trials may not be generalizable to all medically ill patients. Furthermore, the existing trials failed to consider an appropriate VTE risk score predictive tool or bleeding risk assessment prior to initiating the anticoagulant agent. It is also worth mentioning that none of the existing tools for VTE risk prediction have been undergone impact analysis. Future studies to evaluate for impact analysis of a joint VTE-bleeding risk score and to randomize patients at the discharge to receive either of the treatment arms are necessary to address these complex issues. 
Table 3 COVID-19 Related Coagulopathy Post-Discharge Management per Various Guideline Societies ${ }^{52}$

\begin{tabular}{|c|c|}
\hline Society Guideline & Post-Hospital Discharge COVID-19 Patients \\
\hline American society of hematology (ASH) & $\begin{array}{l}\text { - Reasonable to consider FDA approved post discharge prophylactic anticoagulation } \\
\text { with the Rivaroxaban, Betrixaban, or aspirin in patients with low risk of bleeding } \\
\text { and high risk of coagulation. }\end{array}$ \\
\hline Anticoagulation forum (ACF) & $\begin{array}{l}\text { - Routine post discharge VTE prophylaxis is not recommended, but FDA approved } \\
\text { agents can be considered if low risk for bleeding and high risk for VTE including } \\
\text { intubated, sedated, and paralyzed for multiple days. } \\
\text { - Enoxaparin in addition to betrixaban or rivaroxaban can be considered. } \\
\text { - The duration of extended anticoagulation therapy differs based on the use agent } \\
\text { and is as } 31-39 \text { days for rivaroxaban, 35-42 days for betrixaban, and 6-14 days for } \\
\text { enoxaparin. }\end{array}$ \\
\hline $\begin{array}{l}\text { Scientific and Standardization Committee-International } \\
\text { Society of thrombosis. Hemostasis (SCC-ISTH) }\end{array}$ & $\begin{array}{l}\text { - FDA approved post discharge prophylactic anticoagulation with the Rivaroxaban, } \\
\text { Betrixaban, or Enoxaparin in patients with low risk of bleeding and high risk of } \\
\text { coagulation. } \\
\text { - In high risk patients the duration is } 14 \text { days at least and up to } 30 \text { days. }\end{array}$ \\
\hline American College of chest physicians $(\mathrm{ACCP})^{53}$ & $\begin{array}{l}\text { - No anticoagulation unless in patients at low risk of bleeding and if emerging data } \\
\text { suggest clinical benefit. }\end{array}$ \\
\hline Italian Society on Thrombosis and Haemostasis ${ }^{54}$ & $\begin{array}{l}\text { - Prophylaxis should be continued throughout the hospitalization and for an addi- } \\
\text { tional } 7 \text { to } 10 \text { days' post-discharge. }\end{array}$ \\
\hline Center of Disease Control and Prevention (CDC) & $\begin{array}{l}\text { - Routine post discharge VTE prophylaxis is not recommended, but FDA approved } \\
\text { agents can be considered if low risk for bleeding and high risk for VTE using criteria } \\
\text { from clinical trials. }\end{array}$ \\
\hline American College of Cardiology (ACC) & $\begin{array}{l}\text { - Low molecular weight heparin or DOACs can be considered for up to } 45 \text { days in } \\
\text { patients at high risk for VTE (ie, D-dimer }>2 \text { times the upper limit, reduced } \\
\text { mobility, active cancer) and low risk of bleeding. }\end{array}$ \\
\hline
\end{tabular}

Abbreviations: DOAC, direct oral anticoagulant; FDA, Food and Drug Administration; VTE, venous thromboembolism.

\section{Abbreviations}

ACCP, American College of Chest Physicians; ACP, American College of Physicians; APEX, Acute Medically Ill Venous Thromboembolism Prevention with Extended Duration Betrixaban; ARO, Academic Research Organizations; ARR, absolute risk reduction; ASH, American Society of Hematology; CI, confidence interval; $\mathrm{CrCl}$, creatinine clearance; CRO, Contract Research Organization; CRNM, clinically relevant non-major bleeding; CUS, compressible ultrasound; DOACs, direct oral anticoagulant agents; DVT, deep vein thrombosis; FDA, Food and Drug Administration; HR, hazard ratio; ICU, intensive care unit; IMPROVE, International Medical Prevention Registry on Venous Thromboembolism; MACE, major adverse cardiovascular events; MARINER, Medically Ill Patient Assessment of Rivaroxaban versus Placebo in Reducing PostDischarge Venous Thrombo-Embolism Risk; MI, myocardial infarction; MALLEGAN, Multicenter, rAndomized, parallel Group Efficacy and safety study for the prevention of venous thromboembolism in hospitalized medically iLL patients comparing rivaroxabAN with enoxaparin; NATF, North American Thrombosis Forum; NCB, net clinical benefit; NNT, number needed to treat; NT-proBNP, N-terminal fragment of B-type natriuretic peptide; OR, odds ratio; PE, pulmonary embolism; $\mathrm{RR}$, relative risk; SAP, statistical analysis plan; VTE, venous thromboembolism.

\section{Disclosure}

The authors reported no conflicts of interest for this work.

\section{References}

1. Gibson CM, Spyropoulos AC, Cohen AT, et al. The IMPROVEDD VTE risk score: incorporation of D-Dimer into the IMPROVE score to improve venous thromboembolism risk stratification. TH Open. 2017;1 (1):e56. doi:10.1055/s-0037-1603929

2. Heit JA, Crusan DJ, Ashrani AA, Petterson TM, Bailey KR. Effect of a near-universal hospitalization-based prophylaxis regimen on annual number of venous thromboembolism events in the US. Blood. 2017;130(2):109-114. 
3. Cohen AT, Spiro TE, Büller HR, et al. Extended-duration rivaroxaban thromboprophylaxis in acutely ill medical patients: MAGELLAN study protocol. $J$ Thromb Thrombolysis. 2011;31(4):407-416. doi:10.1007/s11239-011-0549-x

4. Cohen AT, Spiro TE, Büller HR, et al. Rivaroxaban for thromboprophylaxis in acutely ill medical patients. $N$ Engl $J$ Med. 2013;368:513-523. doi:10.1056/NEJMoa1111096

5. Cohen AT, Harrington R, Goldhaber SZ, et al. The design and rationale for the acute medically ill venous thromboembolism prevention with extended duration betrixaban (APEX) study. Am Heart J. 2014;167(3):335-341. doi:10.1016/j.ahj.2013.11.006

6. Raskob GE, Spyropoulos AC, Zrubek J, et al. The MARINER trial of rivaroxaban after hospital discharge for medical patients at high risk of VTE. Thromb Haemost. 2016;115(06):1240-1248. doi:10.1160/ TH15-09-0756

7. Cohen AT, Harrington RA, Goldhaber SZ, et al. Extended thromboprophylaxis with betrixaban in acutely ill medical patients. $N$ Engl J Med. 2016;375(6):534-544. doi:10.1056/NEJMoa1601747

8. Gibson CM, Goldhaber SZ, Cohen AT, et al. When academic research organizations and clinical research organizations disagree: processes to minimize discrepancies prior to unblinding of randomized trials. Am Heart J. 2017;189:1-8. doi:10.1016/j. ahj.2017.03.018

9. Arbetter DF, Jain P, Yee MK, et al. Competing risk analysis in a large cardiovascular clinical trial: an APEX substudy. Pharm Stat. 2017;16 (6):445-450. doi:10.1002/pst.1823

10. Gibson CM, Korjian S, Chi G, et al. Comparison of fatal or irreversible events with extended-duration betrixaban versus standard dose enoxaparin in acutely ill medical patients: an APEX trial substudy. $J$ Am Heart Assoc. 2017;6(7):e006015. doi:10.1161/ JAHA.117.006015

11. Nafee T, Gibson CM, Yee MK, et al. Reduction of cardiovascular mortality and ischemic events in acute medically ill patients: an APEX Substudy. Circulation. 2019;139(9):1234-1236. doi:10.1161/ CIRCULATIONAHA.118.038654

12. Gibson CM, Chi G, Halaby R, et al. Extended-duration betrixaban reduces the risk of stroke versus standard-dose enoxaparin among hospitalized medically ill patients: an APEX trial substudy (Acute medically ill venous thromboembolism prevention with extended duration betrixaban). Circulation. 2017;135(7):648-655. doi:10.1161/CIRCULATIONAHA.116.025427

13. Chi G, Yee MK, Amin AN, et al. Extended-duration betrixaban reduces the risk of rehospitalization associated with venous thromboembolism among acutely ill hospitalized medical patients: findings from the APEX trial (acute medically ill venous thromboembolism prevention with extended duration betrixaban trial). Circulation. 2018;137(1):91-94. doi:10.1161/CIRCULATIONAHA.117.031187

14. Chi G, Goldhaber SZ, Hull RD, et al. Thrombus burden of deep vein thrombosis and its association with thromboprophylaxis and D-dimer measurement: insights from the APEX trial. Thromb Haemost. 2017;117(12):2389-2395. doi:10.1160/TH17-08-0538

15. Cohen A, Spiro T, Spyropoulos A, et al. D-dimer as a predictor of venous thromboembolism in acutely ill, hospitalized patients: a subanalysis of the randomized controlled MAGELLAN trial. J Thromb Haemost. 2014;12(4):479-487. doi:10.1111/jth.12515

16. Gibson CM, Jennings LK, Chi G, et al. Association of D-dimer levels with clinical event rates and the efficacy of betrixaban versus enoxaparin in the APEX trial. TH Open. 2018;2(1):e16. doi:10.1055/ s-0037-1615288

17. Gibson CM, Nafee T, Yee MK, et al. Symptomatic event reduction with extended-duration betrixaban in acute medically ill hospitalized patients. Am Heart J. 2018;198:84-90. doi:10.1016/j.ahj.2017.12.015

18. Yee MK, Gibson CM, Nafee T, et al. Characterization of major and clinically relevant non-major bleeds in the APEX trial. TH Open. 2019;3(2):e103. doi:10.1055/s-0039-1685496
19. Yee MK, Nafee T, Daaboul Y, et al. Increased benefit of betrixaban among patients with a history of venous thromboembolism: a post-hoc analysis of the APEX trial. $J$ Thromb Thrombolysis. 2018;45(1):1-8. doi:10.1007/s11239-017-1583-0

20. Gibson CM, Halaby R, Korjian S, et al. The safety and efficacy of full-versus reduced-dose betrixaban in the acute medically ill VTE (Venous Thromboembolism) prevention with extended-duration betrixaban (APEX) trial. Am Heart J. 2017;185:93-100. doi:10.1016/j.ahj.2016.12.004

21. Chi G, Gibson CM, Kalayci A, et al. Extended-duration betrixaban versus shorter-duration enoxaparin for venous thromboembolism prophylaxis in critically ill medical patients: an APEX trial substudy. Intensive Care Med. 2019;45(4):477-487. doi:10.1007/s00134-019-05565-6

22. Ageno W, Lopes RD, Yee MK, et al. Extended prophylaxis of venous thromboembolism with betrixaban in acutely ill medical patients with and without cancer: insights from the APEX trial. J Thromb Thrombolysis. 2020;49(2):214-219. doi:10.1007/s11239-019-01943-5

23. Ageno W, Lopes RD, Yee MK, et al. Net-clinical benefit of extended prophylaxis of venous thromboembolism with betrixaban in medically ill patients aged 80 or more. J Thromb Haemost. 2019;17 (12):2089-2098. doi:10.1111/jth.14600

24. Chi G, Januzzi JL, Korjian S, et al. N-terminal pro-B-type natriuretic peptide and the risk of stroke among patients hospitalized with acute heart failure: an APEX trial substudy. J Thromb Thrombolysis. 2017;44(4):457-465. doi:10.1007/s11239-017-1552-7

25. Chi G, Gibson CM, Hernandez AF, et al. Association of anemia with venous thromboembolism in acutely ill hospitalized patients: an APEX trial substudy. Am J Med. 2018;131(8):972.e1-972. e7. doi:10.1016/j.amjmed.2018.03.031

26. Chi G, Gibson CM, Liu Y, et al. Inverse relationship of serum albumin to the risk of venous thromboembolism among acutely ill hospitalized patients: analysis from the APEX trial. Am J Hematol. 2019;94(1):21-28. doi:10.1002/ajh.25296

27. Mebazaa A, Spiro TE, Büller HR, et al. Predicting the risk of venous thromboembolism in patients hospitalized with heart failure. Circulation. 2014;130(5):410-418. doi:10.1161/ CIRCULATIONAHA.113.003126

28. Spyropoulos AC, Lipardi C, Xu J, et al. Improved benefit risk profile of rivaroxaban in a subpopulation of the MAGELLAN Study. Clin Appl Thromb Hemost. 2019;25:1076029619886022. doi:10.1177/ 1076029619886022

29. Cohoon KP, De Sanctis Y, Haskell L, McBane RD, Spiro TE. Rivaroxaban for thromboprophylaxis among patients recently hospitalized for acute infectious diseases: a subgroup analysis of the MAGELLAN study. J Thromb Haemost. 2018;16(7):1278-1287. doi: $10.1111 /$ jth. 14146

30. Spyropoulos AC, Ageno W, Albers GW, et al. Rivaroxaban for thromboprophylaxis after hospitalization for medical illness. $N$ Engl J Med. 2018;379(12):1118-1127. doi:10.1056/NEJMoa1805090

31. Spyropoulos AC, Ageno W, Albers GW, et al. Post-discharge prophylaxis with rivaroxaban reduces fatal and major thromboembolic events in medically ill patients. $J$ Am Coll Cardiol. 2020;75 (25):3140-3147. doi:10.1016/j.jacc.2020.04.071

32. Nafee T, Gibson CM, Travis R, et al. Machine learning to predict venous thrombosis in acutely ill medical patients. Res Pract Thromb Haemost. 2020;4(2):230-237. doi:10.1002/rth2.12292

33. Qaseem A, Chou R, Humphrey LL, Starkey M, Shekelle P. Venous thromboembolism prophylaxis in hospitalized patients: a clinical practice guideline from the American College of Physicians. Ann Intern Med. 2011;155(9):625-632. doi:10.7326/0003-4819-1559-201111010-00011

34. Kahn SR, Lim W, Dunn AS, et al. Prevention of VTE in nonsurgical patients: antithrombotic therapy and prevention of thrombosis, 9th ed: American College of Chest Physicians Evidence-Based Clinical Practice Guidelines. Chest. 2012;141(2Suppl):e195S-e226S. doi:10.1378/chest.11-2296 
35. Schünemann HJ, Cushman M, Burnett AE, et al. American Society of Hematology 2018 guidelines for management of venous thromboembolism: prophylaxis for hospitalized and nonhospitalized medical patients. Blood Adv. 2018;2(22):3198-3225. doi:10.1182/ bloodadvances.2018022954

36. Chi G, Sharfaei S, Jafarizade M, Kahe F, Liu Y. Extended or shorter prophylaxis for venous thromboembolism in acutely ill hospitalized patients: updated meta-analysis of randomized trials. Vasc Med. 2019;24(2):156-158. doi:10.1177/1358863X18818319

37. Liew AY, Piran S, Eikelboom JW, Douketis JD. Extended-duration versus short-duration pharmacological thromboprophylaxis in acutely ill hospitalized medical patients: a systematic review and meta-analysis of randomized controlled trials. J Thromb Thrombolysis. 2017;43(3):291-301. doi:10.1007/s11239-016-1461-1

38. Barkoudah E, Piazza G, Hecht TE, et al. Extended venous thromboembolism prophylaxis in medically ill patients: an NATF anticoagulation action initiative. Am J Med. 2020;133:1-27. doi:10.1016/j. amjmed.2019.12.001

39. Chi G, Goldhaber S, Kittelson J, et al. Effect of extended-duration thromboprophylaxis on venous thromboembolism and major bleeding among acutely ill hospitalized medical patients: a bivariate analysis. J Thromb Haemost. 2017;15(10):1913-1922. doi:10.1111/jth.13783

40. Weitz JI, Raskob GE, Spyropoulos AC, et al. Thromboprophylaxis with rivaroxaban in acutely ill medical patients with renal impairment: insights from the MAGELLAN and MARINER trials. Thromb Haemost. 2020;120(03):515-524. doi:10.1055/s-0039-1701009

41. Jamil A, Jamil U, Singh K, Khan F, Chi G. Extended thromboprophylaxis with betrixaban or rivaroxaban for acutely ill hospitalized medical patients: meta-analysis of prespecified subgroups. Crit Pathw Cardiol. 2021;20(1):16-24. doi:10.1097/HPC.0000000000000232

42. Miao B, Chalupadi B, Clark B, et al. Proportion of US hospitalized medically ill patients who may qualify for extended thromboprophylaxis. Clin Appl Thromb Hemost. 2019;25:1076029619850897. doi:10.1177/1076029619850897

43. Guy H, Laskier V, Fisher M, Bucior I, Deitelzweig S, Cohen AT. Budget impact analysis of betrixaban for venous thromboembolism prophylaxis in nonsurgical patients with acute medical illness in the United Kingdom. Expert Rev Pharmacoecon Outcomes Res. 2020;20 (3):259-267. doi:10.1080/14737167.2019.1629905

44. Guy H, Laskier V, Fisher M, et al. Cost-effectiveness of betrixaban compared with enoxaparin for venous thromboembolism prophylaxis in nonsurgical patients with acute medical illness in the United States. Pharmacoeconomics. 2019;37(5):701-714. doi:10.1007/ s40273-018-0757-8
45. Middeldorp S, Coppens M, van Haaps TF, et al. Incidence of venous thromboembolism in hospitalized patients with COVID-19. J Thromb Haemost. 2020;18(8):1995-2002. doi:10.1111/jth.14888

46. Wichmann D, Sperhake J-P, Lütgehetmann M, et al. Autopsy findings and venous thromboembolism in patients with COVID-19: a prospective cohort study. Ann Intern Med. 2020;173(4):268-277.

47. Chi G, Lee JJ, Jamil A, et al. Venous thromboembolism among hospitalized patients with COVID-19 undergoing thromboprophylaxis: a systematic review and meta-analysis. J Clin Med. 2020;9 (8):2489. doi:10.3390/jcm9082489

48. Porfidia A, Valeriani E, Pola R, Porreca E, Rutjes AW, Di Nisio M. Venous thromboembolism in patients with COVID-19: systematic review and meta-analysis. Thromb Res. 2020;196:67-74. doi:10.1016/j.thromres.2020.08.020

49. Klok FA, Kruip M, Van Der Meer N, et al. Confirmation of the high cumulative incidence of thrombotic complications in critically ill ICU patients with COVID-19: an updated analysis. Thromb Res. 2020;191:148-150.

50. Kalayci A, Gibson CM, Chi G, et al. Asymptomatic deep vein thrombosis is associated with an increased risk of death: insights from the APEX trial. Thromb Haemost. 2018;118(12):2046-2052. doi:10.1055/s-0038-1675606

51. Goldhaber SZ. Thromboembolism prophylaxis for patients discharged from the hospital: easier said than done*. J Am Coll Cardiol. 2020;75(25):3148. doi:10.1016/j.jacc.2020.05.023

52. Flaczyk A, Rosovsky RP, Reed CT, Bankhead-Kendall BK, Bittner EA, Chang MG. Comparison of published guidelines for management of coagulopathy and thrombosis in critically ill patients with COVID 19: implications for clinical practice and future investigations. Crit Care. 2020;24(1):1-13. doi:10.1186/s13054020-03273-y

53. Moores LK, Tritschler T, Brosnahan S, et al. Prevention, diagnosis, and treatment of VTE in patients with coronavirus disease 2019: CHEST guideline and expert panel report. Chest. 2020;158 (3):1143-1163. doi:10.1016/j.chest.2020.05.559

54. Marietta M, Ageno W, Artoni A, et al. COVID-19 and haemostasis: a position paper from Italian Society on Thrombosis and Haemostasis (SISET). Blood Transfus. 2020;18(3):167.
Therapeutics and Clinical Risk Management

\section{Publish your work in this journal}

Therapeutics and Clinical Risk Management is an international, peerreviewed journal of clinical therapeutics and risk management, focusing on concise rapid reporting of clinical studies in all therapeutic areas, outcomes, safety, and programs for the effective, safe, and sustained use of medicines. This journal is indexed on PubMed Central, CAS,
EMBase, Scopus and the Elsevier Bibliographic databases. The manuscript management system is completely online and includes a very quick and fair peer-review system, which is all easy to use. Visit http://www.dovepress.com/testimonials.php to read real quotes from published authors. 